\title{
Vitamin D Deficiency and Insufficiency in Northeast Tennessee
}

\author{
Arun Joseph Kattakayam1, Donovan Reed ${ }^{2}$, Sajin M. Karakattu3, Beth Bailey ${ }^{4}$, \\ Millard Ray Lamb5 , Paul 0. Lewis ${ }^{6}$, Dima Youssef ${ }^{*}$ \\ ${ }^{1}$ Department of Internal Medicine, Norwalk Hospital, Norwalk, CT, USA \\ ${ }^{2}$ Texas Oculoplastics Consultants, TOC Eye \& Face, Austin, TX, USA \\ ${ }^{3}$ Department of Internal Medicine, Division of Pulmonary and Critical Care, East Tennessee State University, Johnson City, TN, USA \\ ${ }^{4}$ Department of Family Medicine, East Tennessee State University, Johnson City, TN, USA \\ ${ }^{5}$ Recovery Associates, Johnson City, TN, USA \\ ${ }^{6}$ Department of Pharmacy, Johnson City Medical Center, Johnson City, TN, USA \\ ${ }^{7}$ Department of Internal Medicine, Division of Infectious Diseases, East Tennessee State University, Johnson City, TN, USA \\ Email:^estecina@hotmail.com
}

How to cite this paper: Kattakayam, A.J., Reed, D., Karakattu, S.M., Bailey, B., Lamb, M.R., Lewis, P.O. and Youssef, D. (2020) Vitamin D Deficiency and Insufficiency in Northeast Tennessee. Health, 12, 1085-1094. https://doi.org/10.4236/health.2020.129079

Received: June 10, 2020

Accepted: August 31, 2020

Published: September 2, 2020

Copyright $\odot 2020$ by author(s) and Scientific Research Publishing Inc. This work is licensed under the Creative Commons Attribution International License (CC BY 4.0).

http://creativecommons.org/licenses/by/4.0/

\section{(c) (i) Open Access}

\begin{abstract}
Background: The role of vitamin D in population subgroups throughout the world continues to be a topic of interest among researchers. Current evidence demonstrates that treating vitamin $\mathrm{D}$ deficiency plays a significant role in improving mortality in hospitalized patients, reducing hospital length of stay, and boosting innate immune system. Vitamin $\mathrm{D}$ levels vary with age, gender, body mass index (BMI) and geographical area. The purpose of this study is to evaluate vitamin D levels in a cohort of patients in Northeast Tennessee. Study: This institutional review board-approved, retrospective study evaluated vitamin D levels of patients obtained from Mcleod Cancer and Blood Center. Vitamin D levels were collected over a 2-year period and classified as deficient $(<20 \mathrm{ng} / \mathrm{mL})$, insufficient $(20-30 \mathrm{ng} / \mathrm{mL})$, or replete $(>30 \mathrm{ng} / \mathrm{mL})$. Data were then stratified based on patient characteristics (age, gender, body mass index (BMI), race, seasons, and place of residence) and compounds of vitamin D (D2 and D3). Results: There were 2011 individuals included, with only $44.3 \%$ having replete levels and $21.4 \%$ with levels less than $20 \mathrm{ng} / \mathrm{mL}$. Females with vitamin D deficiency are more likely to have levels below 20 $\mathrm{ng} / \mathrm{ml}$ compared to males ( $18.6 \%$ vs. $23 \%$, respectively, $\mathrm{p}=0.003$ ). Regarding $\mathrm{BMI}$, the highest levels were reported in normal weight and overweight. With regards to age, advanced age $(\geq 70)$ was associated with the highest levels and most replete patients. Winter months were associated with the lowest levels of vitamin D. Higher vitamin D levels were found in individuals over 70 years, normal weight and overweight category. Conclusion: Testing vitamin D levels in high-risk groups becomes of utmost importance in areas with longer
\end{abstract}


winter months, obese and underweight patients. Vitamin D levels should be routinely tested and treated in vulnerable populations.

\section{Keywords}

Vitamin D, Vitamin D Deficiency, Vitamin D Insufficiency, Northeast Tennessee

\section{Introduction}

Vitamin D is an essential fat-soluble vitamin highly dependent on sun exposure for dermal synthesis as intake from food is minimal [1]. Vitamin D is biologically inactive and requires a 2 -step conversion to 25 -hydroxyvitamin $\mathrm{D}$ in the liver, the major circulating form, and then 1,25-dihydroxyvitamin $\mathrm{D}$, the active form, in the kidney [1]. Vitamin D plays a major role in calcium and bone homeostasis as well as other cellular functions.

Vitamin D deficiency is an under-recognized yet worldwide epidemic spanning all demographics. It is estimated that over $40 \%$ of adults have levels less than $20 \mathrm{mg} / \mathrm{mL}$ according to the National Health and Nutrition Examination Survey [2]. Groups at highest risk include those confined to indoors and advanced age [2]. Other high-risk groups include dark skinned, obese, hospitalized patients, institutionalized persons, or those with malabsorptive conditions. Initial complications of vitamin $\mathrm{D}$ deficiency include reduced intestinal absorption of calcium and phosphate, leading to secondary parathyroidism, phosphaturia, bone demineralization, rickets (children), and osteomalacia (adults) [3]. This is often accompanied by bone pain or tenderness, fractures, muscle weakness, and difficulty walking [3]. Further complications include diabetes mellitus, cardiovascular complications, autoimmune disorders, and cancer [4].

The benefits of treating vitamin D deficiency span further than improvements to the musculoskeletal system. Research has also demonstrated that treating vitamin D deficiency plays a significant role in improving mortality in hospitalized patients, reducing hospital length of stay, and boosting innate immune system [5]. While vitamin D deficiency is well established, treatment is often lacking due to the condition being under-recognized. The purpose of this study was to evaluate vitamin D levels in Northeast Tennessee and to identify risk factors among subgroups.

\section{Methods}

\subsection{Participants and Procedures}

This study was conducted at the Mcleod Cancer and Blood center in the Southeastern United States after approval by the institutional review board at East Tennessee State University. Data were obtained electronically through retrospective review after protected health information was redacted. The cohort included all adult patients seen at a Hematology-Oncology or Internal Medicine 
visit at an outpatient clinic who had at least one 25-hydroxyvitamin D level checked over a period of two years from 2013-2014. Patients included were seen as part of routine medical care and not volunteers from the community. No patients were excluded. The 25-hydroxyvitamin D assay was determined via immunochemiluminometric assay (Labcorp, Burlington, North Carolina). A vitamin $\mathrm{D}$ value for each patient was extracted from the electronic medical record. Additional data extracted included age, gender, race, body mass index and ZIP code of residence. During this period, the patients who didn't have all parameters collected were excluded. If available, vitamin D2 (ergocalciferol) and vitamin D3 (cholecalciferol) were also recorded and stratified.

\subsection{Data Analysis}

Vitamin D levels were analyzed as both continuous and ordinal variables with deficiency defined as 25 hydroxyvitamin $\mathrm{D}<20 \mathrm{ng} / \mathrm{ml}$, insufficiency defined as $20-30 \mathrm{ng} / \mathrm{ml}$ and replete defined as $>30 \mathrm{ng} / \mathrm{ml}$ [6]. Data were obtained electronically through a database query after removal of personal information, and statistical analyses were performed using PASW 125 (IBM Inc., version 18.0; Armonk, NY). All variables were checked for outliers and normality of distributions before analyses were performed. Outlying values on vitamin D level were identified and recoded to three standard deviations above the mean for subsequent analysis. T-tests and $\chi^{2}$ tests were used to examine bivariate associations. Multiple regression analyses (linear and logistic) were used for adjusted analyses, comparing patients on vitamin D levels. Statistical significance was defined as a $\mathrm{p}$ value $<0.05$

\section{Results}

There were 2011 patients included in this study. The majority of patients were females $(67.4 \%)$ and over the age of $70(52.9 \%)$. Patients were almost exclusively white $(98.4 \%)$, with the majority $(68.3 \%)$ were overweight or obese. Less than half of the patients are vitamin D replete $(44.3 \%)$, and $21.6 \%$ of patients had a vitamin D level less than $20 \mathrm{ng} / \mathrm{mL}$. Seasonal testing was similar, with the exception of slightly less testing occurring during summer (14.4\%), see Table 1.

Mean vitamin D values were recorded in Table 2 and stratified by patient demographic and season. Males and females did not differ significantly on overall vitamin $\mathrm{D}(29 \%$ vs. $29.5 \%$, respectively, $\mathrm{p}=0.4)$. Advancing age was associated with higher levels of vitamin $\mathrm{D}$ levels, with age 70 and older having a mean level of $31.7 \mathrm{ng} / \mathrm{mL}$, age $5-69$ years of $29.2 \mathrm{ng} / \mathrm{mL}$, and age less than 50 years of $27.8 \mathrm{ng} / \mathrm{mL}, \mathrm{p}<0.001$. BMI also had a significant correlation $(\mathrm{p}<0.001)$ with the highest mean levels seen in normal range $(32.4 \mathrm{ng} / \mathrm{mL})$, followed by overweight $(21.4 \mathrm{ng} / \mathrm{mL})$, obese $(28 \mathrm{ng} / \mathrm{mL})$, and lastly underweight $(27.3$ $\mathrm{ng} / \mathrm{mL}$ ). Finally, there was a significant correlation with seasonal testing ( $\mathrm{p}=$ $0.001)$. Vitamin D values were lowest in the winter months $(28.8 \mathrm{ng} / \mathrm{mL})$ and all other months over $30 \mathrm{ng} / \mathrm{mL}$. 
Values were reported as replete $(\geq 30 \mathrm{ng} / \mathrm{mL})$ or not replete $(<30 \mathrm{ng} / \mathrm{mL})$ in Table 3 based on classification and in Table 4 based on patient characteristics. When stratifying by patient characteristics, Vitamin deficiency occurred the highest in females, age 50 - 69, underweight, and Fall, while replete Vitamin D levels were most likely to be seen in females, age 70+, normal weight, and Summer. However, statistically, males and females did not differ significantly in vitamin D level or in the percentage that are replete. Gender differences were evident when comparing levels below $30 \mathrm{ng} / \mathrm{mL}$. Specifically, women who were not vitamin D replete were much more likely than men to have levels below 20 $\mathrm{ng} / \mathrm{mL}$ than men ( $23 \%$ vs. $18.6 \%$, respectively, $\mathrm{p}=0.003)$. Patients age 70 and older were significantly more likely to be vitamin $\mathrm{D}$ replete than patients either

Table 1. Description of participating patients.

\begin{tabular}{|c|c|c|}
\hline Patient Characteristic & Mean or $\%(\mathrm{~N})$ & Range \\
\hline \multicolumn{3}{|l|}{ Gender } \\
\hline Male & $32.6 \%(656)$ & \\
\hline Female & $67.4 \%(1355)$ & \\
\hline Age & 69.5 & $22-106$ \\
\hline$<50$ years & $11.5 \%(229)$ & \\
\hline $50-69$ years & $35.7 \%(713)$ & \\
\hline $70+$ years & $52.9 \%(1057)$ & \\
\hline \multicolumn{3}{|l|}{ Race } \\
\hline White & $98.4 \%(1979)$ & \\
\hline Other & $1.6 \%(32)$ & \\
\hline Body Mass Index & 28.7 & $14.0-77.8$ \\
\hline Underweight $(<18.5)$ & $2.4 \%(47)$ & \\
\hline Normal (18.5 - 24.9) & $29.4 \%(570)$ & \\
\hline Overweight $(25-29.9)$ & $32.5 \%(630)$ & \\
\hline Obese $(30+)$ & $35.8 \%(694)$ & \\
\hline Vitamin D (25(OH)) & 29.3 & $2.2-112.5$ \\
\hline Deficient $(<20)$ & $21.6 \%(435)$ & \\
\hline Insufficient $(20-29)$ & $34.1 \%(686)$ & \\
\hline Replete (30+) & $44.3 \%(890)$ & \\
\hline Vitamin D2 & 2.83 & $0-80.3$ \\
\hline Vitamin D3 & 27.4 & $0-96.6$ \\
\hline \multicolumn{3}{|c|}{ Season of Vitamin D Testing } \\
\hline Spring & $28.1 \%(562)$ & \\
\hline Summer & $14.4 \%(287)$ & \\
\hline Fall & $28.1 \%(562)$ & \\
\hline Winter & $29.5 \%(589)$ & \\
\hline
\end{tabular}


Table 2. Patient characteristics and overall vitamin D (25(OH)) levels.

\begin{tabular}{|c|c|c|c|}
\hline Patient Characteristic & Vitamin D Level (IU) & $\mathrm{t} / \mathrm{F}$ & p-value \\
\hline Gender & & 0.92 & 0.359 \\
\hline Male & 29.0 & & \\
\hline Female & 29.5 & & \\
\hline Age & & 9.44 & $<0.001$ \\
\hline$<50$ years & 27.8 & & \\
\hline $50-69$ years & 29.2 & & \\
\hline $70+$ years & 31.7 & & \\
\hline Body Mass Index & & 9.85 & $<0.001$ \\
\hline Underweight $(<18.5)$ & 27.3 & & \\
\hline Normal (18.5 - 24.9) & 32.4 & & \\
\hline Overweight (25 - 29.9) & 31.4 & & \\
\hline Obese $(30+)$ & 28.0 & & \\
\hline Season of Vitamin D Testing & & 5.19 & 0.001 \\
\hline Spring & 30.3 & & \\
\hline Summer & 33.1 & & \\
\hline Fall & 30.1 & & \\
\hline Winter & 28.8 & & \\
\hline
\end{tabular}

Table 3. Patient characteristics and two group vitamin D status.

\begin{tabular}{ccccc}
\hline Patient Characteristic & $<30 \mathrm{ng} / \mathrm{mL}$ & $\geq 30 \mathrm{ng} / \mathrm{mL}$ & $X^{2}$ & p-value \\
\hline Gender & & & 1.58 & 0.209 \\
Male & $57.6 \%$ & $42.4 \%$ & & \\
Female & $54.6 \%$ & $45.4 \%$ & & \\
Age & & & 20.56 & \\
$<50$ years & $59.8 \%$ & $40.2 \%$ & & \\
50 - 69 years & $61.4 \%$ & $38.6 \%$ & & \\
$70+$ years & $51.0 \%$ & $49.0 \%$ & & \\
Body Mass Index & & & 46.76 & \\
Underweight (<18.5) & $55.3 \%$ & $44.7 \%$ & & \\
Normal (18.5 - 24.9) & $47.4 \%$ & $52.6 \%$ & & \\
Overweight (25 - 29.9) & $52.5 \%$ & $47.5 \%$ & & \\
Obese (30+) & $65.7 \%$ & $34.3 \%$ & & \\
Season of Vitamin D Testing & & & & \\
Spring & $55.0 \%$ & $45.0 \%$ & & \\
Summer & $48.1 \%$ & $51.9 \%$ & & \\
Fall & $58.4 \%$ & $41.6 \%$ & & \\
Winter & $58.2 \%$ & $41.8 \%$ & & \\
\hline & & & \\
\hline
\end{tabular}


Table 4. Patient characteristics and three group vitamin D status

\begin{tabular}{|c|c|c|c|c|c|}
\hline Patient Characteristic & $<20 \mathrm{ng} / \mathrm{mL}$ & $20-29 \mathrm{ng} / \mathrm{mL}$ & $\geq 30 \mathrm{ng} / \mathrm{mL}$ & $X^{2}$ & p-value \\
\hline Gender & & & & 11.79 & 0.003 \\
\hline Male & $18.6 \%$ & $39.0 \%$ & $42.4 \%$ & & \\
\hline Female & $23.0 \%$ & $31.7 \%$ & $45.4 \%$ & & \\
\hline Age & & & & 22.75 & $<0.001$ \\
\hline$<50$ years & $23.6 \%$ & $36.2 \%$ & $40.2 \%$ & & \\
\hline $50-69$ years & $25.4 \%$ & $36.0 \%$ & $38.6 \%$ & & \\
\hline $70+$ years & $18.7 \%$ & $32.3 \%$ & $49.0 \%$ & & \\
\hline Body Mass Index & & & & 60.90 & $<0.001$ \\
\hline Underweight $(<18.5)$ & $38.3 \%$ & $17.0 \%$ & $44.7 \%$ & & \\
\hline Normal (18.5 - 24.9) & $16.8 \%$ & $30.5 \%$ & $52.6 \%$ & & \\
\hline Overweight (25 - 29.9) & $18.7 \%$ & $33.8 \%$ & $47.5 \%$ & & \\
\hline Obese $(30+)$ & $27.4 \%$ & $38.3 \%$ & $34.3 \%$ & & \\
\hline Season of Vitamin D Testing & & & & 12.91 & 0.045 \\
\hline Spring & $20.3 \%$ & $34.7 \%$ & $45.0 \%$ & & \\
\hline Summer & $16.4 \%$ & $31.7 \%$ & $51.9 \%$ & & \\
\hline Fall & $24.4 \%$ & $34.0 \%$ & $41.6 \%$ & & \\
\hline Winter & $22.9 \%$ & $35.3 \%$ & $41.8 \%$ & & \\
\hline
\end{tabular}

less than 50 years or 50 - 69 years ( $49 \%$ vs. $40.2 \%$ vs. $38.6 \%$, respectively, p < $0.001)$. When stratifying patients by BMI, patients in the normal weight range experienced had the greatest percentage as replete $(52.6 \%)$, followed by overweight (47.5\%), underweight (44.7\%), and obese (34.3\%). Vitamin D levels were highest in the summer months and lowest in the fall and winter months.

There were 1322 patients that underwent laboratory testing for 25-hydroxy components, D2 and D3. Associations between background characteristics and D2 and D3 values are presented in Table 5. In general, higher Vitamin D2 levels were seen in females, age 70+, underweight, and Spring. Higher Vitamin D3 levels were seen in females, age 70, normal weight, and Summer. The only background characteristic associated with significant differences in D2 levels was gender, with females having significantly higher levels than males (3.1 vs. $2.3 \mathrm{ng} / \mathrm{mL}$, respectively, $\mathrm{p}<0.05)$. Age, BMI, and season of testing had differences in D3 levels with the same pattern of relationships as was found for 25-hydroxyvitamin D.

\section{Discussion}

Based on this study, one in every five individuals had vitamin D levels lower than $20 \mathrm{ng} / \mathrm{ml}$. Higher vitamin D levels were found in individuals over 70 years, the normal weight and overweight category. The only background characteristic associated with vitamin D2 levels was gender; with females having significantly higher levels than males. The lowest levels of vitamin D were found in extremes 
Table 5. Patient characteristics and vitamin D components.

\begin{tabular}{|c|c|c|c|c|}
\hline Patient Characteristic & Vit D2 & $\mathrm{t} / \mathrm{F}$ & Vit D3 & $t / F$ \\
\hline Gender & & $2.05^{*}$ & & 1.48 \\
\hline Male & 2.3 & & 26.8 & \\
\hline Female & 3.1 & & 27.8 & \\
\hline Age & & 1.34 & & $5.37^{\star *}$ \\
\hline$<50$ years & 2.1 & & 25.7 & \\
\hline $50-69$ years & 2.7 & & 26.5 & \\
\hline $70+$ years & 3.1 & & 28.5 & \\
\hline Body Mass Index & & .08 & & $12.13^{* * *}$ \\
\hline Underweight $(<18.5)$ & 3.0 & & 24.3 & \\
\hline Normal (18.5 - 24.9) & 2.8 & & 29.5 & \\
\hline Overweight $(25-29.9)$ & 2.7 & & 28.7 & \\
\hline Obese $(30+)$ & 2.9 & & 24.9 & \\
\hline Season of Vitamin D Testing & & .20 & & $4.93^{* *}$ \\
\hline Spring & 3.0 & & 27.3 & \\
\hline Summer & 2.9 & & 30.3 & \\
\hline Fall & 2.7 & & 27.0 & \\
\hline Winter & 2.7 & & 26.2 & \\
\hline
\end{tabular}

${ }^{*} \mathrm{p}<0.05 ;{ }^{* *} \mathrm{p}<0.01 ;{ }^{* * *} \mathrm{p}<0.001$.

of BMI (underweight and obese). Only normal weight or overweight groups had average values in the replete range.

Greene-Finestone and colleagues studied plasma 25-hydroxyvitamin D levels in patients aged 6 to 17 years old from the Canadian Health Measures Survey. Results demonstrated an inverse relationship between obesity and vitamin D levels [7]. Seo and colleagues studied the association between visceral obesity and vitamin D levels in 260 men and 268 women age 65 and older. It was observed that greater visceral fat and lower muscle mass were associated with lower vitamin D levels in elderly Korean men [8].

The lowest levels of vitamin $\mathrm{D}$ were found in winter months as expected. Tangpricha and colleagues noted that young individuals between 18 and 29 years of age had a greater risk of vitamin D insufficiency, especially during winter months. The study also noted that parathyroid hormone levels were significantly higher in winter months correlating well with low vitamin D levels at the end of winter [9]. Another study used serum 25-hydroxyvitamin D data from 18,875 individuals examined in the Third National Health and Nutrition Examination Survey (NHANES III 1988-1994) and demonstrated vitamin D insufficiency in younger individuals, especially in the winter subgroup [10].

Females with vitamin D deficiency were more likely to have levels below 20 $\mathrm{ng} / \mathrm{ml}$ compared to males. Chen $\mathrm{CH}$ and colleagues studied vitamin $\mathrm{D}$ levels 
among 1839 older adults. Among 617 individuals with vitamin D deficiency, 72.3 percent were women. It was noted that vitamin $\mathrm{D}$ deficiency was more common in women and were associated with lower musculoskeletal health and higher cardiac risk factors [11].

Higher levels of vitamin D were seen with increasing age with only the over 70 age group having an average vitamin $\mathrm{D}$ value in the replete range. A study of 3608 female veterans evaluated between 2001 and 2010 concluded that older women had significantly more vitamin D monitoring and follow-up testing than younger women [12]. This could explain replete levels of vitamin D in age group over 70 years.

Vitamin D deficiency has reached a pandemic state and is associated with increased high cost burdens on the health care system. In a veteran's study conducted by Youssef and colleagues, vitamin D deficient patients with Clostridium difficile infection were found to have a five times higher costs when compared to non-deficient patients [13]. Diagnosing and treating vitamin D deficiency could reduce hospital length of stay and reduce the number of hospitalizations. There have been studies demonstrating the immunomodulatory and antimicrobial effects of vitamin D. Vitamin D decreases levels of TGF- $\beta$ and NF-kappaB activation; and induces production of LL-37 (cathelicidin), which has antimicrobial and antiendotoxin properties [14]. Evans KN and colleagues studied the immunomodulatory role of vitamin $\mathrm{D}$ on human decidual cells from the first and third trimester pregnancies. Decidual NK cells that were treated with 1,25 dihydroxyvitamin D or precursor 25-hydroxyvitamin D showed decreased synthesis of cytokines, such as granulocyte-macrophage colony stimulating factor 2 (CSF2), tumor necrosis factor, and interleukin 6, but increased expression of mRNA for the antimicrobial peptide cathelicidin [15]. A prospective cohort study was conducted on 99 inpatients admitted to an internal medicine teaching service from July through October 2006 at a single private hospital in Johnson City, Tennessee. Of the 99 patients, 53\% were vitamin D deficient or insufficient. The highest frequency of deficiency was in females $<50$ years. The study recommended physicians to have a low threshold for testing blood levels of 1,25-dihydroxyvitamin $\mathrm{D}$ to rule out vitamin $\mathrm{D}$ deficiency [16].

This study is limited to a single geographic location that is almost exclusively made up of white people. While this study supports the widespread issue of Vitamin D deficiency and insufficiency, results may not be extrapolated to other populations in other regions. Additionally, results are limited to those patients seeking medical care, and thus cannot be extrapolated to people within the region that did not seek medical care. For seasonal comparisons, ideally each patient would have a level drawn in each season. As studied here, patients usually had one level drawn, preventing paired comparisons on seasonal variations.

Testing for vitamin D levels becomes crucial in areas with longer winter months, obese and underweight patients. Studies have shown that ordinary doses of vitamin D supplements have reduced total mortality rates in patients with 
comorbid conditions like cancer, heart disease and diabetes [17]. Treating vitamin D deficiency has also shown to reduce financial burden, hospital length of stay and mortality [18]. Another study identified the positive benefits of vitamin D on the body's immune system led to a reduction in hospital admissions, readmissions and length of stay [19]. Taking into account the immense data on the beneficial effects of vitamin $\mathrm{D}$, we recommend that vitamin $\mathrm{D}$ levels should be routinely tested and treated in the high-risk groups.

\section{Conclusion}

Vitamin D deficiency is widespread in Northeast Tennessee. The most vulnerable populations for deficiency included females, patients underweight, and age 50 - 69 years. Testing vitamin D levels in high-risk groups becomes of utmost importance in states with longer winter months, obese and underweight patients. Increased vigilance of vitamin D deficiency is warranted to ensure proper identification and treatment in vulnerable groups.

\section{Conflicts of Interest}

The authors declare no conflicts of interest regarding the publication of this paper.

\section{References}

[1] Christakos, S., Ajibade, D.V., Dhawan, P., et al. (2010) Vitamin D: Metabolism. Endocrinology and Metabolism Clinics of North America, 39, 243. https://doi.org/10.1016/j.ecl.2010.02.002

[2] Forrest, K.Y. and Stuhldreher, W.L. (2011) Prevalence and Correlates of Vitamin D Deficiency in US Adults. Nutrition Research, 31, 48-54. https://doi.org/10.1016/j.nutres.2010.12.001

[3] LeBoff, M.S., Kohlmeier, L., Hurwitz, S., et al. (1999) Occult Vitamin D Deficiency in Postmenopausal US Women with Acute Hip Fracture. JAMA, 281, 1505. https://doi.org/10.1001/jama.281.16.1505

[4] Wimalawansa, S.J. (2018) Non-Musculoskeletal Benefits of Vitamin D. The Journal of Steroid Biochemistry and Molecular Biology, 175, 60-81. https://doi.org/10.1016/j.jsbmb.2016.09.016

[5] Youssef, D.A., Ranasinghe, T., Grant, W.B., et al. (2012) Vitamin D's Potential to Reduce the Risk of Hospital-Acquired Infections. Dermatoendocrinology, 4, 167-175. https://doi.org/10.4161/derm.20789

[6] Holick, M.F. (2008) The Vitamin D Deficiency Pandemic and Consequences for Nonskeletal Health: Mechanisms of Action. Molecular Aspects of Medicine, 29, 361-368. https://doi.org/10.1016/j.mam.2008.08.008

[7] Greene-Finestone, L.S., Garriguet, D., Brooks, S., et al. (2017) Overweight and Obesity Are Associated with Lower Vitamin D Status in Canadian Children and Adolescents. Paediatrics \& Child Health, 22, 438-444. https://doi.org/10.1093/pch/pxx116

[8] Seo, J.A., Cho, H., Eun, C.R., et al. (2012) Association between Visceral Obesity and Sarcopenia and Vitamin D Deficiency in Older Koreans: The Ansan Geriatric Study. Journal of the American Geriatrics Society, 60, 700-706. 
https://doi.org/10.1111/j.1532-5415.2012.03887.x

[9] Tangpricha, V., Pearce, E.N., Chen, T.C., et al. (2002) Vitamin D Insufficiency among Free-Living Healthy Young Adults. The American Journal of Medicine, 112, 659-662. https://doi.org/10.1016/S0002-9343(02)01091-4

[10] Looker, A.C., Dawson-Hughes, B., Calvo, M.S., et al. (2002) Serum 25-Hydroxyvitamin F Status of Adolescents and Adults in Two Seasonal Subpopulations from NHANES III. Bone, 30, 771-777. https://doi.org/10.1016/S8756-3282(02)00692-0

[11] Chen, C.H., Liu, L.K., Chen, M.J., et al. (2018) Associations between Vitamin D Deficiency, Musculoskeletal Health, and Cardiometabolic Risk among Community-Living People in Taiwan: Age and Sex-Specific Relationship. Medicine (Baltimore), 97, e 13886. https://doi.org/10.1097/MD.0000000000013886

[12] Alazzeh, A., Cooper, M.M., Bailey, B., Youssef, D.A., et al. (2015) Vitamin D Status and Monitoring in Female Veterans. Women Health, 55, 367-377. https://doi.org/10.1080/03630242.2015.1022685

[13] Youssef, D., Grant, W.B. and Peiris, A.N. (2012) Vitamin D Deficiency: A Potential Risk Factor for Clostridium difficile Infection. Risk Management and Healthcare Policy, 5, 115-116. https://doi.org/10.2147/RMHP.S36781

[14] Youssef, D.A., Peiris, A.N., Kelley, J.L., et al. (2013) The Possible Roles of Vitamin $\mathrm{D}$ and Curcumin in Treating Gonorrhea. Medical Hypotheses, 81, 131-135. https://doi.org/10.1016/j.mehy.2013.04.013

[15] Evans, K.N., Nguyen, L., Chan, J., et al. (2006) Effects of 25-Hydroxyvitamin D3 and 1,25-Dihydroxyvitamin D3 on Cytokine Production by Human Decidual Cells. Biology of Reproduction, 75, 816-822. https://doi.org/10.1095/biolreprod.106.054056

[16] Kuriacose, R. and Olive, K.E. (2014) Vitamin D Insufficiency/Deficiency Management. Southern Medical Journal, 107, 66-70. https://doi.org/10.1097/SMJ.0000000000000051

[17] Autier, P. and Gandini, S. (2007) Vitamin D Supplementation and Total Mortality: A Meta-Analysis of Randomized Controlled Trials. Archives of Internal Medicine, 167, 1730-1737. https://doi.org/10.1001/archinte.167.16.1730

[18] Grant, W.B., Cross, H.S., Garland, C.F., et al. (2009) Estimated Benefit of Increased Vitamin D Status in Reducing the Economic Burden of Disease in Western Europe. Progress in Biophysics and Molecular Biology, 99, 104-113. https://doi.org/10.1016/j.pbiomolbio.2009.02.003

[19] Matthews, L.R., Ahmed, Y., Wilson, K.L., et al. (2012) Worsening Severity of Vitamin D Deficiency Is Associated with Increased Length of Stay, Surgical Intensive Care Unit Cost, and Mortality Rate in Surgical Intensive Care Unit Patients. The American Journal of Surgery, 204, 37-43.

https://doi.org/10.1016/j.amjsurg.2011.07.021 